\title{
Mapeamento cartográfico do município de Paulo Jacinto-AL
}

\author{
Felippe Pessoa de Melo'
}

'Universidade Federal de Sergipe, São Cristóvão, SE. Brasil.

\begin{abstract}
Resumo
O presente trabalho tem como objetivo confeccionar a base cartográfica do Município de Paulo Jacinto-AL, para isso foram utilizadas as tecnologias do Sensoriamento Remoto e Sistema de Informações Geográficas-SIG, as quais possibilitaram a confecção de um banco de dados geográficos com informações matriciais e vetoriais. Tornando possível realizar as correlações entre os distintos modelos de dados em um mesmo ambiente virtual, o que maximiza a qualidade dos produtos oriundos dessas inter-relações. Dessa forma foram confeccionadas as cartas temáticas referentes: hipsometria, drenagem, cobertura vegetal, geologia, solos, clima, isoietas, isotermas... De posse desse material o município de Paulo Jacinto-Al passou a ter materiais cartográficos que facilitaram a tomada de decisões para implementação de políticas públicas que estejam em consonância com o desenvolvimento sustentável.
\end{abstract}

Palavras-chave: Base cartográfica, tecnologias, políticas públicas e desenvolvimento sustentável.

\begin{abstract}
The present study aims to confect the basemap of Paulo Jacinto county in the state of Alagoas. Technologies of Remote Sensing and Geographic Information System-GIS were used in the process, which enabled the manufacturing of a geographic database with matrix and vector information. This way, it is possible to perform the correlations between different data models in a single virtual environment, which maximizes the quality of the products originated in these interrelationships. Thematic maps were made regarding: hypsometry, drainage, vegetation, geology, soils, climate, isohyets, and isotherms. For possessing such material, the city of Paulo Jacinto-Al now has cartographic materials that facilitated decision making for implementation of public policies that are in line with sustainable development.
\end{abstract}

Keywords: . Basemap, technologies, public policies and sustainable development. 


\section{INTRODUÇÃO}

O município de Paulo Jacinto não possui uma base de dados cartográficos própria, para suprir essa carência são utilizadas cartas temáticas do Instituto Brasileiro de Geografia e Estatística-IBGE, mas as escalas utilizadas pelo IBGE não possibilitam analisar de maneira mais detalhada as características geográficas da área em questão, um bom exemplo é o mapa físico do estado de alagoas que está na escala de 1:700.000. O que impossibilita utilizar essas informações para ações relacionadas à implantação de planos gestores, simulações de enchentes, planejamentos urbanos, administração de recursos minerais...

Para subsidiar essa carência municipal foram utilizadas as tecnologias do Sensoriamento Remoto e SIG, essas tecnologias possibilitaram a confecção de um banco de dados geográficos, com informações matriciais e vetoriais. O que permitiu realizar correlações entre essas distintas formas de dados e possibilitou a confecção das cartas temáticas de Paulo Jacinto-AL, referentes aos seus aspectos geográficos. Facilitando a implantação de medidas para recuperação de áreas degradadas e maximizando a qualidade de vida da população local.

\section{I.I LOCALIZAÇÃo DA ÁREA DE ESTUdo}

O município de Paulo Jacinto está localizado na porção centro-norte do estado de Alagoas, estando a 108km de Maceió, capital alagoana. Faz divisa com as seguintes cidades alagoanas: Quebrangulo, Palmeira dos Índios, Mar Vermelho e Viçosa (Figura 1). As cidades polos mais próximas são: Viçosa, que fica a $21.4 \mathrm{~km}$ de distância, Palmeira dos Índios a $33.7 \mathrm{~km}$ e Arapiraca a $69.3 \mathrm{~km}$.

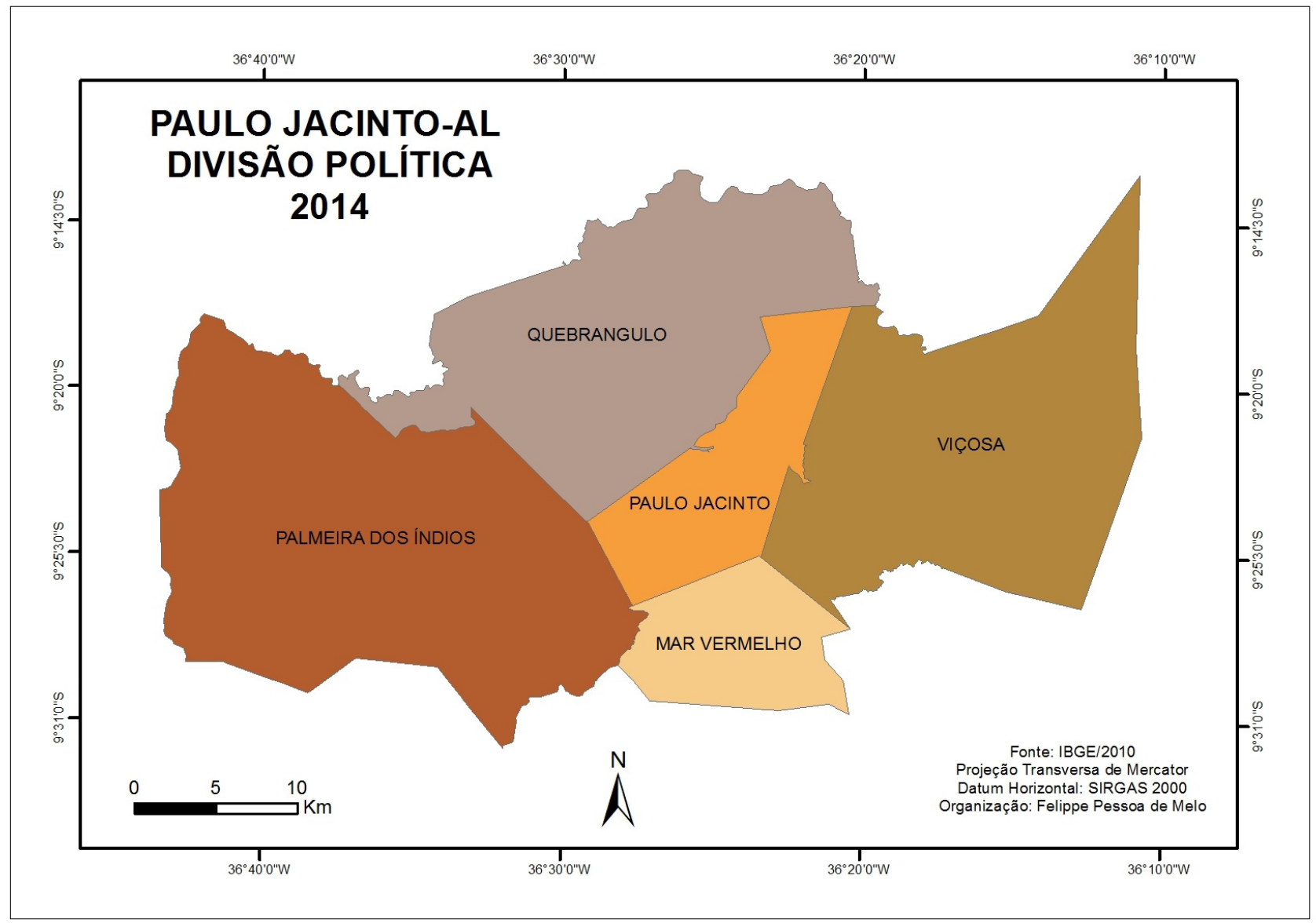

Figura 1. Localização Geográfica da área de Estudo. (Fonte: IBGE/2010). 


\section{METODOLOGIA}

Realizou-se uma pesquisa de gabinete, com a finalidade de conhecer o material bibliográfico referente à temática e baixar os dados vetoriais e matriciais correspondentes ao perímetro do local de estudo. Logo em seguida confeccionou-se um banco de dados geográficos georreferenciados no SIG ArcGIS. De posse dos dados em um ambiente virtual foram feitas as correlações entre as informações, o que possibilitou a confecção de cartas temáticas com escalas entre $1.5 \mathrm{~km}$ e $5 \mathrm{~km}$.

Posteriormente realizou-se a pesquisa de campo objetivando confirmar as informações obtidas em gabinete, editar e reambular quando necessário. Após essa etapa as cartas temáticas foram reimpressas.

\section{RESULTADOS E DISCUSSÕES}

Paulo Jacinto apresenta cotas altimétricas que oscilam de 230 a 600m (Figura 2), modelo de classificação taxonômica do relevo proposto por Ross (1992), foram encontradas seis Unidades Morfológicas ou Padrões de Formas (Tabela 1).

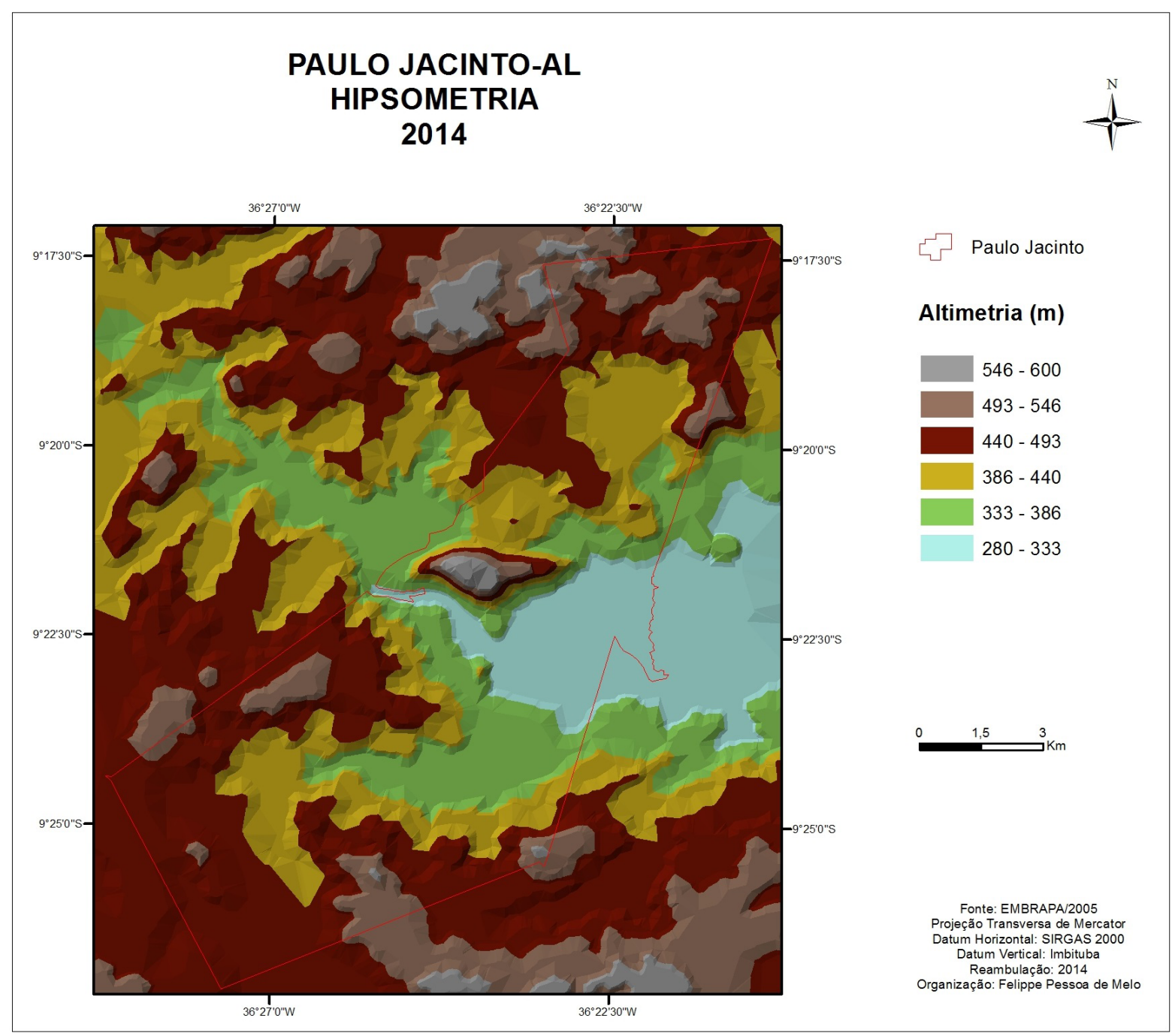

Figura 2. Topografia de Paulo Jacinto-Al e das Áreas Circunvizinhas. (Fonte: EMBRAPA/2005). 
Tabela 1. Subdivisões do Modelado. (Fonte: EMBRAPA/2005).

\begin{tabular}{c|c|c|c|c|c}
\hline Altimetria (m) & Área $\left(\mathrm{Km}^{2}\right)$ & Percentual (\%) & Altimetria (m) & Área $\left(\mathrm{Km}^{2}\right)$ & Percentual (\%) \\
\hline $546-600$ & 11,19 & 0,94 & $386-440$ & 294,40 & 24,82 \\
\hline $493-546$ & 118,76 & 10,01 & $333-386$ & 196,35 & 16,55 \\
\hline $440-493$ & 445,48 & 35,58 & $280-333$ & 119,82 & 10,10 \\
\hline \multicolumn{5}{c|}{ Área Total $\left(\mathrm{Km}^{2}\right)$} & \multicolumn{5}{c}{1.186} \\
\hline
\end{tabular}

Geologicamente o município está inserido em seis unidades distintas (Tabela 2), dentre elas a que possui maior representatividade é a dos Granitoides Indiscriminados (Figura 3).

\begin{tabular}{|c|c|}
\hline Unidades Geológicas & Minerais \\
\hline Belém do São Francisco & $\begin{array}{l}\text { Ortognaisse tonalítico, granítico, migmatito, ortognaisse } \\
\text { granodiorítico e metadiorito. }\end{array}$ \\
\hline Cabrobó (01) & $\begin{array}{l}\text { Metamáfica, metagrauvaca, quartzito, formação ferrífera } \\
\text { bandada, biotita xisto, rocha calcissilicática, biotita gnaisse, } \\
\text { mármore, muscovita-biotita xisto, muscovita-biotita gnaisse, } \\
\text { rocha metaultramáfica, paramigmatito... }\end{array}$ \\
\hline Cabrobó (01) / Migmatitos & Paramigmatito e paragnaisse. \\
\hline Ganitóides Indiscriminados & $\begin{array}{l}\text { Metatonalito, ortognaisse, metagranito, metagranodiorito, } \\
\text { metamonzodiorito... }\end{array}$ \\
\hline Ouro Branco & Garanodiorito e monzonito. \\
\hline Plúton & $\begin{array}{l}\text { Quartzo álcali-feldspato sienito, quartzo monzonito, quartzo } \\
\text { sienito. }\end{array}$ \\
\hline
\end{tabular}

Dentro dos limites municipais encontram-se os solos: Latossolos amarelos distróficos e Neossolos litólicos eutróficos (Figura 4). O primeiro possui uma área de $332,62 \mathrm{Km}^{2}$, equivalendo a $28,04 \%$ do território municipal e o segundo tem um perímetro de $853,38 \mathrm{Km}^{2}$, o que corresponde a $71,96 \%$ do município.

Sua cobertura vegetal original era formada principalmente pela caatinga hipoxerófila (Figura 05), com uma área de $1.064,19 \mathrm{Km}^{2}$ o que equivale a $89,72 \%$ do perímetro municipal. Existindo uma pequena presença de uma flora tropical subcaducifólia e subperenifólia na porção sudeste do seu território, equivalente a $121,90 \mathrm{Km}^{2}$, ou seja, $10,28 \%$ do território do município.

Atualmente só existem resquícios dessas vegetações, devido a ações como: a retirada da vegetação original para maximização das atividades agrárias, ampliação do sítio urbano, fornecimento de madeira para os fornos das padarias e para os festejos juninos, confecção de estacas para demarcação das propriedades agrícolas...

A remoção da flora ocorreu de forma insustentável, ocasionando diversos problemas geoambientais, dentre eles destacam-se: redução da fauna, intensificação dos processos erosivos, assoreamento do rio Paraíba, minimização do potencial turístico, formação de ilhas de calor, invasão de insetos e aracnídeos nas residências, perda de solos... 


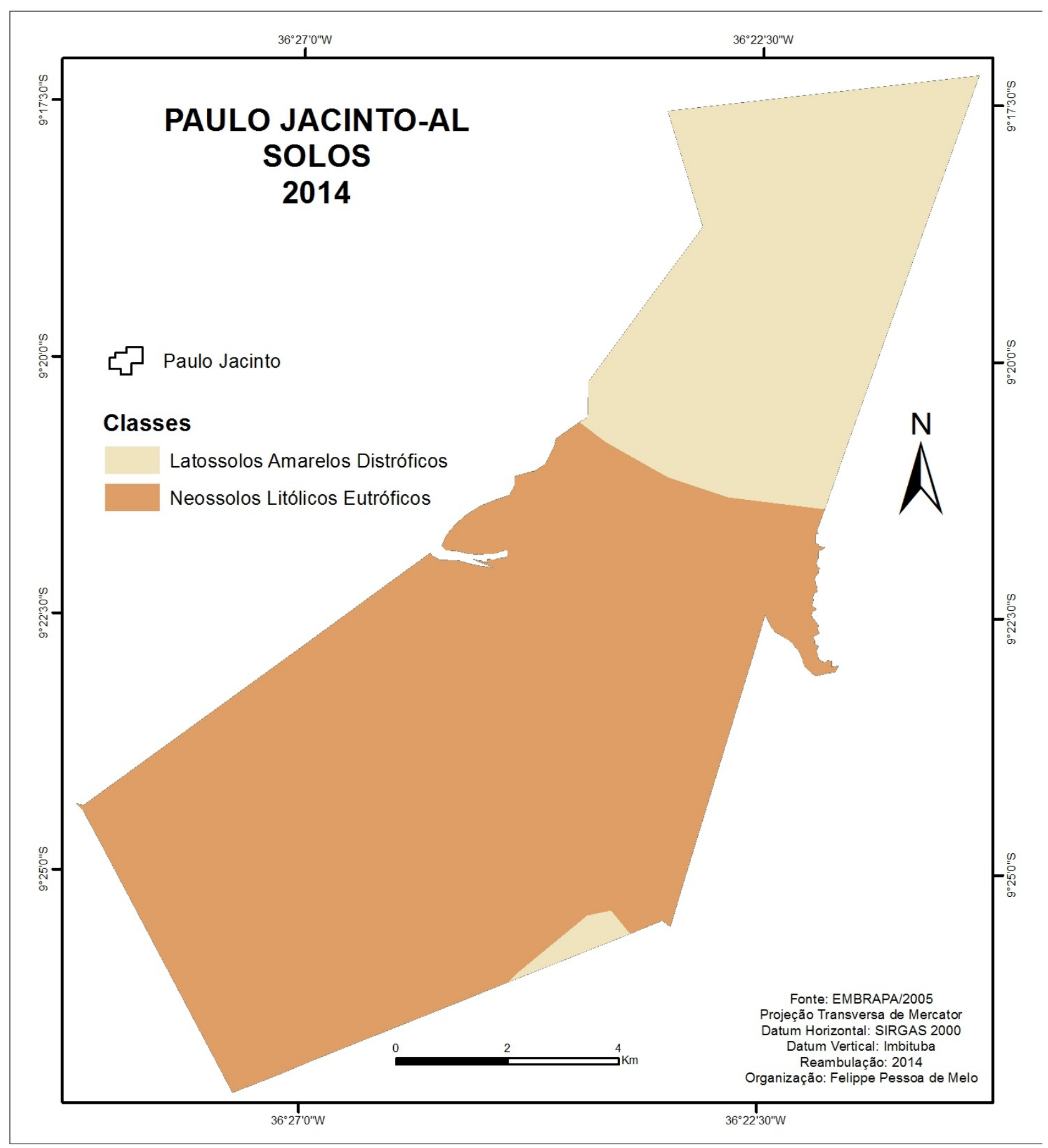

Figura 4. Tipos de solos. (Fonte: EMBRAPA/2005).

O principal rio da sua rede hidrográfica é o Paraíba (Figura 06), o qual está com sua mata ciliar desmatada. O que está provocando o seu assoreamento, contaminação das suas águas, diminuição da fauna e flora aquática...

O território municipal está sob o domínio do clima semiárido, a média térmica anual é de $23^{\circ} \mathrm{C}$. Suas precipitações podem atingir $1750 \mathrm{~mm}$ nos períodos mais chuvosos (Figura 7), que vão de novembro a abril e $100 \mathrm{~mm}$ nas épocas mais secas (Figura 8), de maio a outubro. Podendo ocorrer eventuais variações nesse sistema climático. Principalmente devido à forte interferência antrópica na paisagem. 


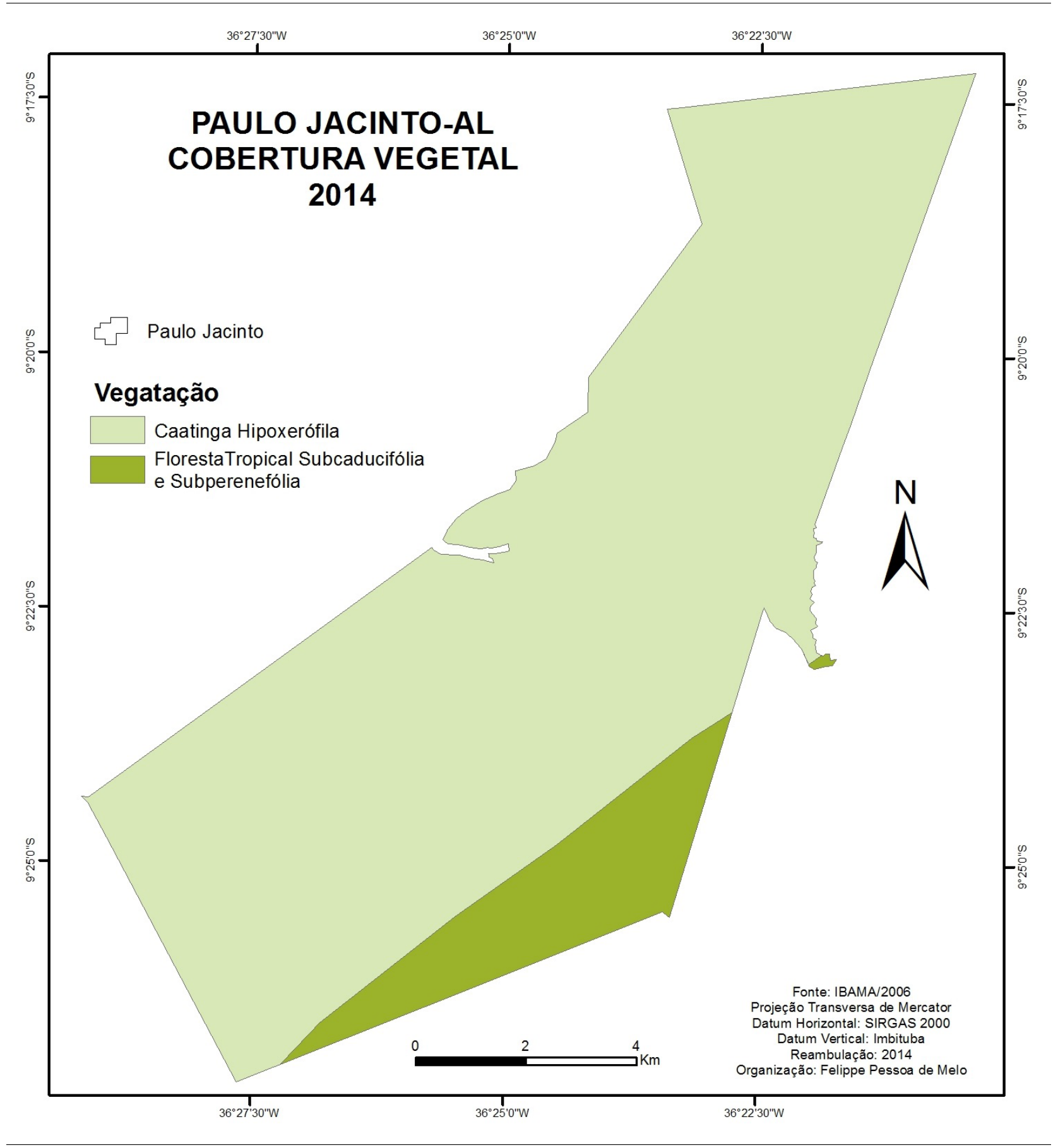

Figura 5. Cobertura Vegetal. (Fonte: IBAMA/2006).

Destacam-se no seu modelado as feições planas e fortemente onduladas (Figura 9), ocupando um perímetro de $1.063 .36 \mathrm{Km}^{2}$, ou seja, $89,65 \%$ do território municipal. As feições com características suavemente onduladas e onduladas ocupam uma área de $122,64 \mathrm{Km}^{2}$, o que corresponde a $10,35 \%$ do modelado.

Essas peculiaridades do relevo aliadas a falta de cobertura vegetal o tornam bem susceptível a deslizamentos e desmoronamentos, principalmente nos períodos mais chuvosos. Colocando em risco de vida a população local 


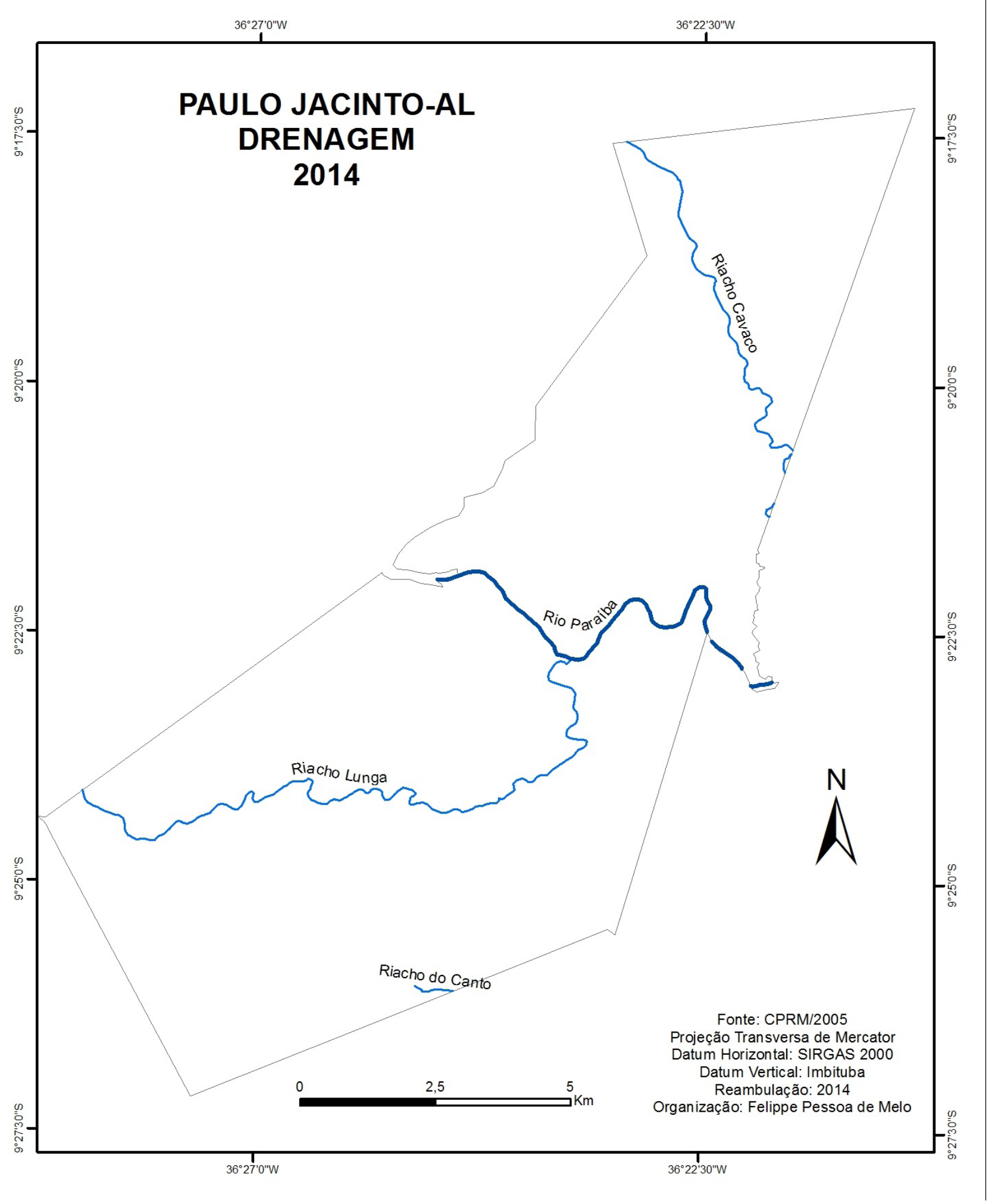

Figura 6. Sistema Hidrográfico. (Fonte: CPRM/2005) 


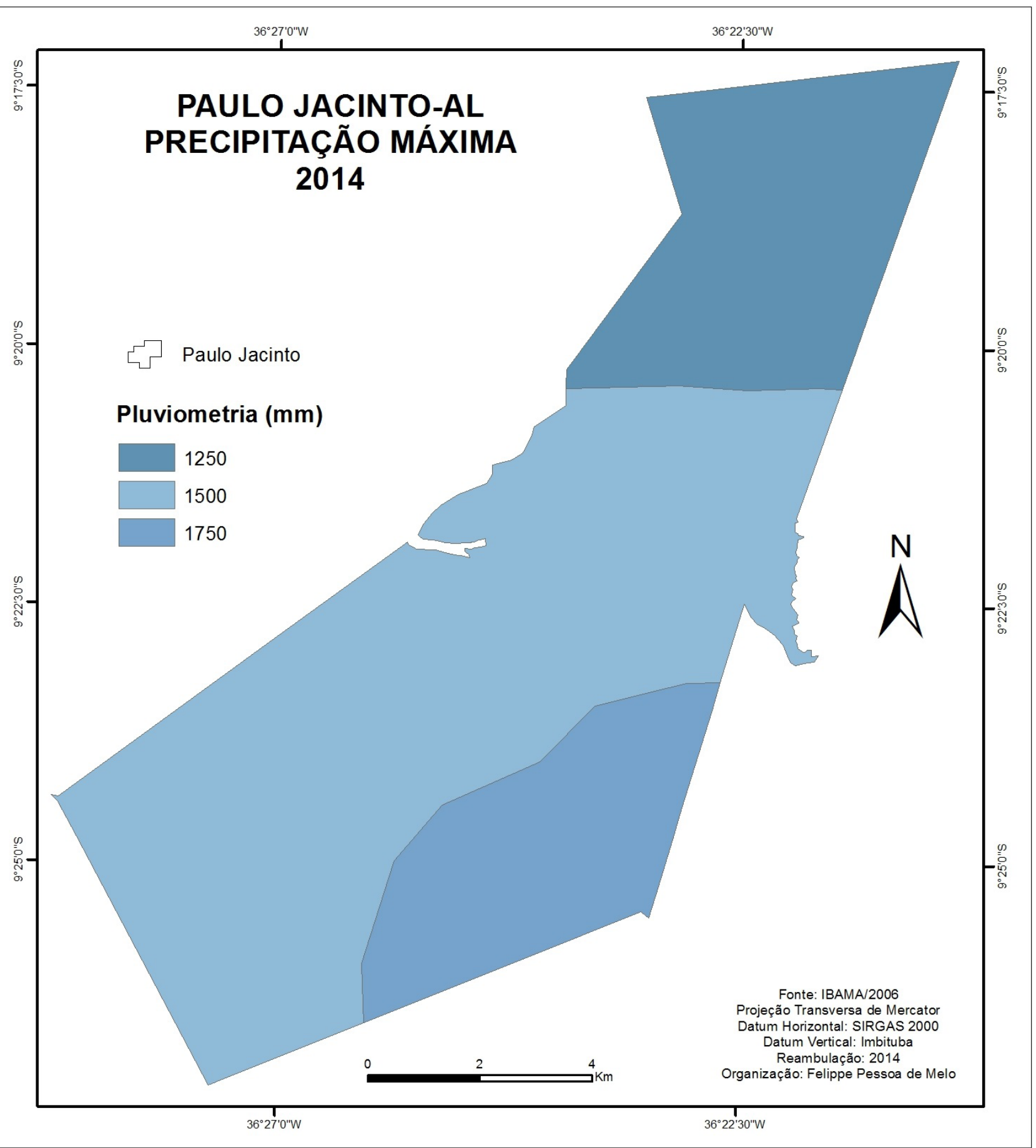

Figura 7. Precipitações. (Fonte: IBAMA/2006).

$10,35 \%$ do território de Paulo Jacinto apresentam condições favoráveis à agricultura (Figura 10), devido à boa fertilidade dos solos (Figura 11). Dessa forma o município pode exercer a função de celeiro agrícola regional.

O restante do perímetro apresenta condições favoráveis para prática da pecuária leiteira e de corte. Podendo assim fornecer carne e derivados do leite para cidades circunvizinhas. 


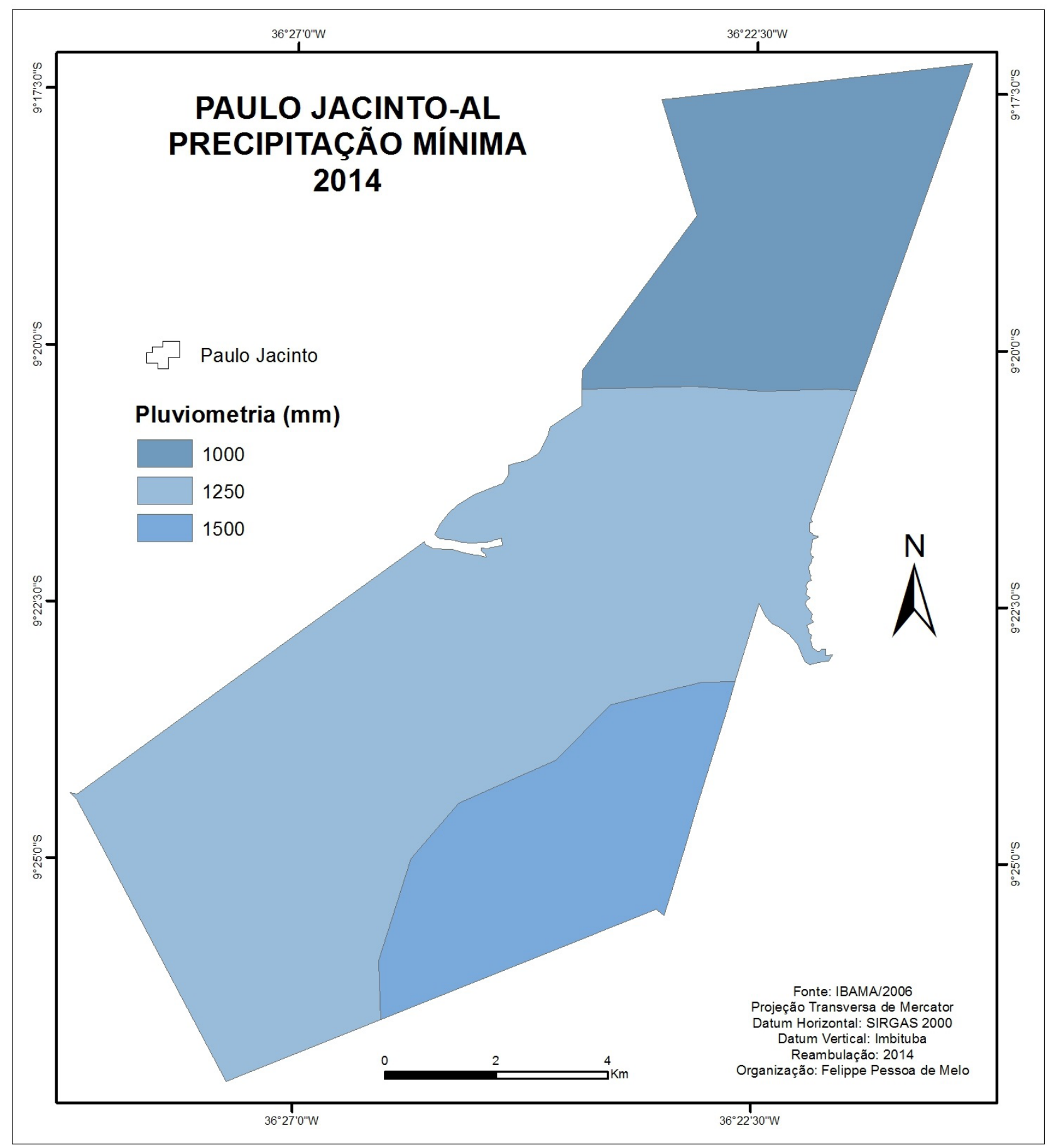

Figura 8. Precipitações. (Fonte: IBAMA/2006). 


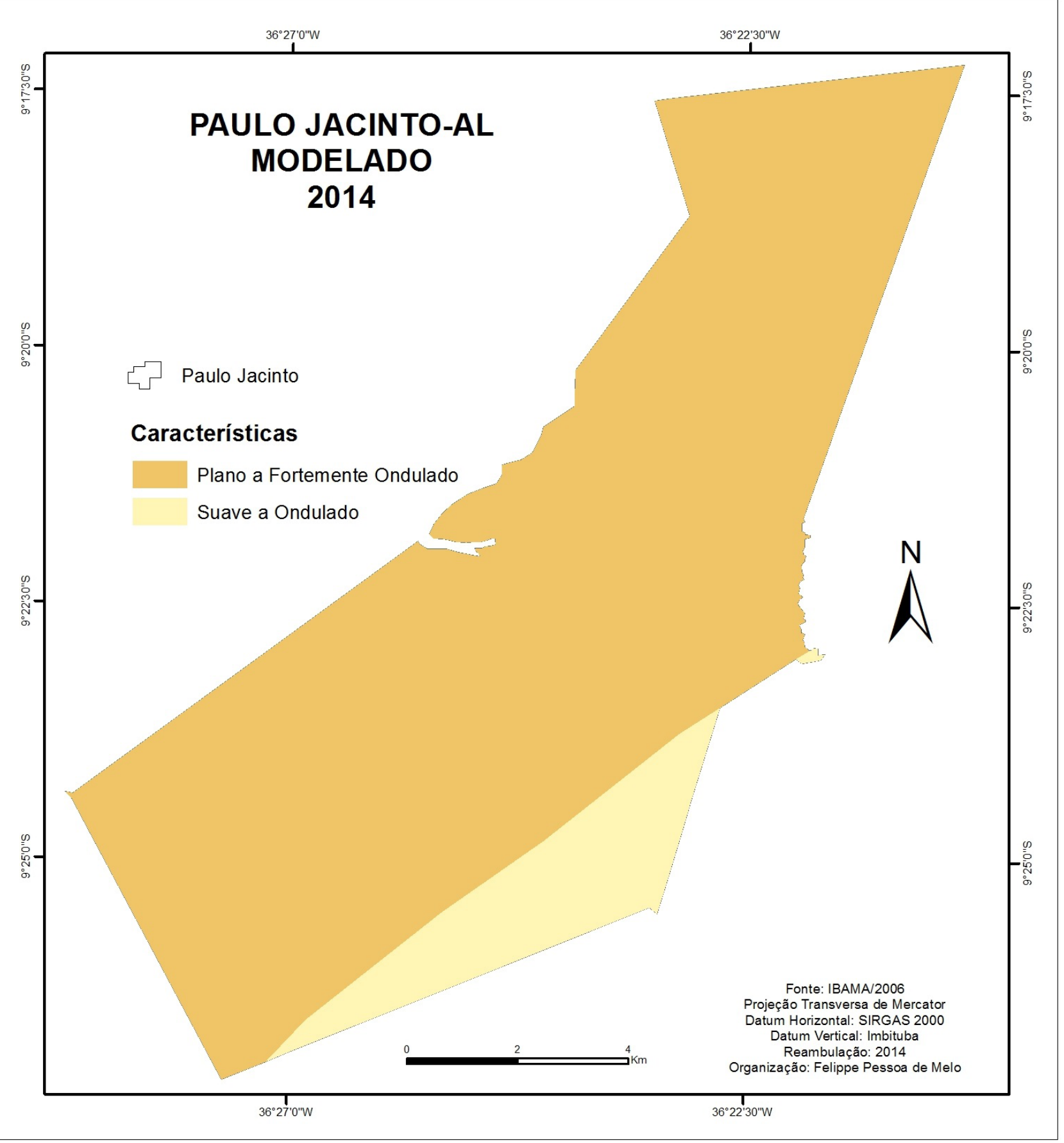

Figura 9. Características do Modelado. (Fonte: IBAMA/2006). 


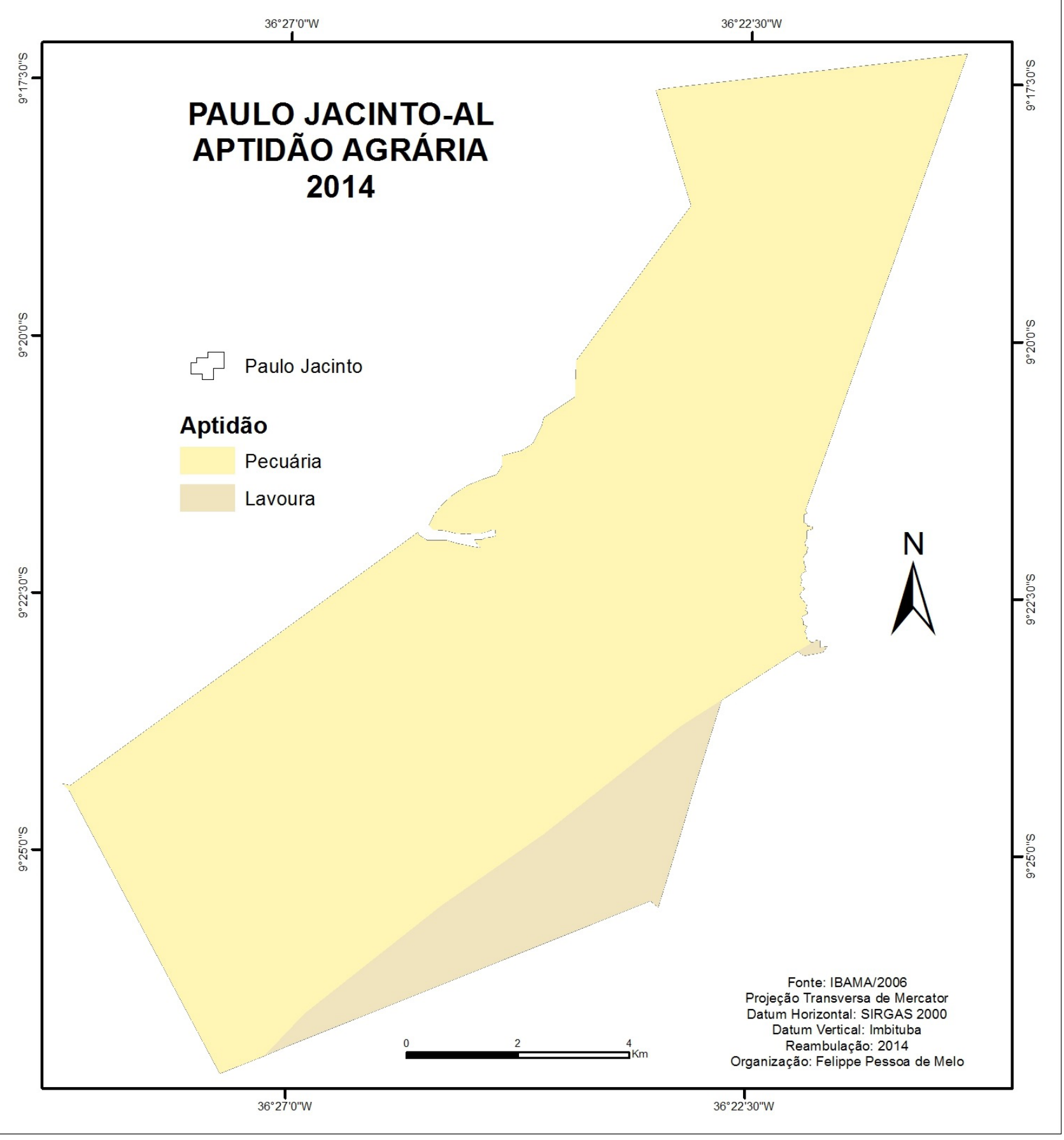

Figura 10. Potencial Agrário. (Fonte: IBAMA/2006). 


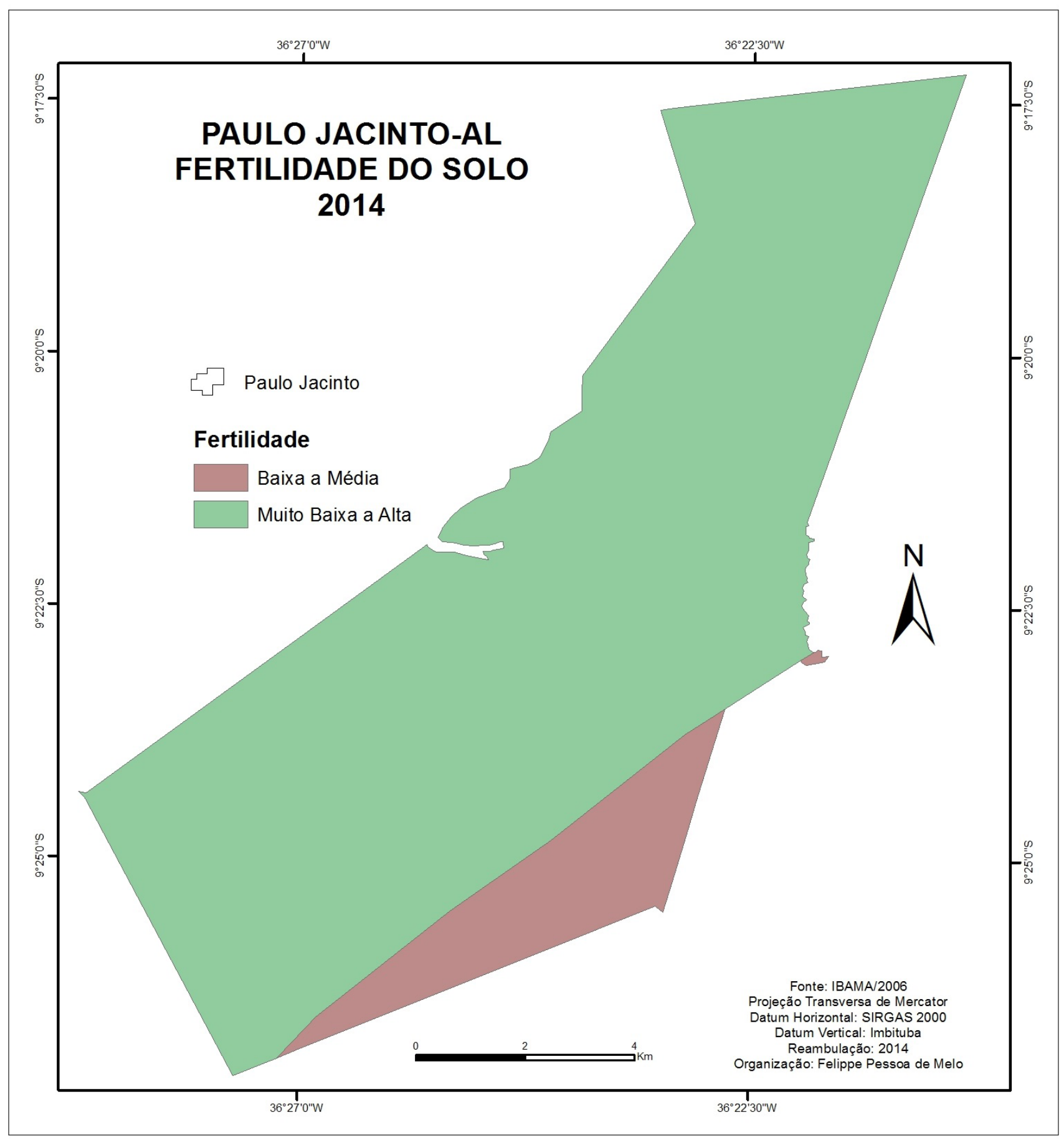

Figura 11. Fertilidade dos Solos. (Fonte: IBAMA/2006).

\section{CONCLUSÕES}

Utilizando as tecnologias do Sensoriamento Remoto e Sistema de Informações Geográficas-SIG, foi possível confeccionar as cartas temáticas referentes à divisão política, hipsometria, geologia, solos, cobertura vegetal drenagem, precipitação máxima e mínima, modelado, aptidão agrária e fertilidade do solo.

Esse material cartográfico subsidiará o município de Paulo Jacinto na tomada de decisões que necessitem de informações geográficas em escalas que possibilitem uma boa percepção do território em relação as suas características físicas. Já que a escala que o município dispunha anteriormente essa 
informações era de 1:700.000.

E agora é de 1:150.000 para a hipsometria; 1:200.000 para a geologia, solos, cobertura vegetal, precipitação máxima e mínima, modelado, aptidão agrária e fertilidade do solo e 1:250.000 para drenagem.

A cata na escala de $1: 150.000$, representa uma melhora de $78.58 \%$, as representações cartográficas na escala de 1:200.000, correspondem a uma melhora de $71.43 \%$ e a carta na escala de 1:250.000, é equivalente a uma melhora de $64.29 \%$. Portanto os resultados obtidos foram considerados satisfatórios.

\section{REFERÊNCIAS}

CPRM-Companhia de Pesquisa de Recursos Minerais. Geobank. Disponível em: < http://geobank.sa.cprm. gov.br/>. Acesso em 22 de mar. 2013.

EMBRAPA-Empresa Brasileira de Pesquisa Agropecuária. Brasil em Relevo. Disponível em: < $\underline{\text { http: } / / w w w . ~}$ relevobr.cnpm.embrapa.br/index.htm>. Acesso em 10 de jan. 2012.

IBAMA- Instituto Brasileiro do Meio Ambiente e dos Recursos Naturais Renováveis. Temas Vetoriais Formato Shapefile. Disponível em: <http://siscom.ibama.gov.br/shapes>. Acesso em 22 de jan. 2013.

IBGE-Instituto Brasileiro de Geografia e Estatística. Banco de Dados. Disponível em: < http://www.ibge.gov.br/ home/default.php>. Acesso em 20 de mar. 2012.

INMET-Instituto Nacional de Meteorologia. Estações e Dados. Disponível em: < $\underline{\text { http://www.inmet.gov.br/por- }}$ tal>. Acesso em 22 de mai. 2012.

INPE-Instituto Nacional de Pesquisas Espaciais. Catálogo de Imagens. Disponível em: < $\underline{\text { http://www.dgi.inpe. }}$ br/CDSR/>. Acesso em 18 de mar. 2012.

Portal Brasil. Código Florestal. Disponível em: <http://www.brasil.gov.br/sobre/meio-ambiente/legislacao-e-orgaos/codigo-florestal>. Acesso em: 26 de mar. 2013.

ROSS, J. L. S. 1992. O Registro Cartográfico dos Fatos Geomórficos e a Questão da Taxonomia do Relevo. São Paulo. Revista do Departamento de Geografia. 6: 17-29. 